\title{
Actinomicosis pélvica relacionada a dispositivos intrauterinos
}

Pelvic actinomicosis in relation with uterine devices

\author{
${ }^{1}$ Dr. Christopher Guerrero Hines \\ Hospital Rafael Ángel Calderón Guardia, San José, Costa Rica \\ (1D) https://orcid.org/0000-0002-5370-9377 \\ ${ }^{2}$ Dr. Manrique Pizarro Madrigal \\ Hospital Rafael Ángel Calderón Guardia, San José, Costa Rica \\ (D) https://orcid.org/0000-0002-0812-322x \\ ${ }^{3}$ Dra. Nancy Chacón Campos \\ Hospital Rafael Ángel Calderón Guardia, San José, Costa Rica \\ (D) https://orcid.org/0000-0002-5058-5452
}

Recibido $14 / 12 / 2021$
Corregido $02 / 01 / 2022$
Aceptado $10 / 01 / 2022$

\section{RESUMEN}

La actinomicosis pélvica es una infrecuente, pero importante infección crónica causada por una bacteria gram positiva, del género actinomices. La actinomicosis puede afectar varios órganos y tejidos del cuerpo, la forma pélvica suele presentarse como un absceso tubo-ovárico y con menor frecuencia como una actinomicosis pélvica invasiva (API). La API se propaga por contigüidad desde el aparato genital hacia las vísceras adyacentes, originando un tumor pélvico difuso, pseudotumoral, que a menudo se confunde con una neoplasia pélvica. Su causa más común es el uso de dispositivos intrauterinos, los cuales son utilizados mayoritariamente para el control de la natalidad. La API representa un gran desafío para el ginecólogo por las dificultades en su diagnóstico y manejo.

PALABRAS CLAVE: Actinomyces; actinomicosis; dispositivos intrauterinos.

\section{ABSTRACT}

Pelvic actinomycosis is an uncommon but important chronic infection caused by a gram positive bacterium of the actinomyces genus. Actinomices can affect different organs and tissues of the body, and the pelvic form usually is presented as a tubo-ovarian abscess and less frequently, as an invasive pelvic actinomycosis (IPA). IPA spreads contiguously from the genital tract to the adjacent viscera, causing a diffuse pseudotumoral pelvic tumor, that is often mistaken for a 
pelvic neoplasm. Its most common cause is the use of intrauterine devices, which are used mostly for birth control. The IPA represents a great challenge for the gynecologist due to the difficulties in its diagnosis and management.

KEYWORDS: Actinomyces, actinomycosis; intrauterine devices; abscess.

${ }^{1}$ Médico general, graduado de la Universidad Internacional de las Américas (UIA), Cód. MED16761. Correo: chrisgh0591@gmail.com

${ }^{2}$ Médico general, graduado de la Universidad de Hispanoamericana (UH). Cód. MED16690 . Correo: manriquepizarro@hotmail.com

${ }^{3}$ Médica general, graduada de la Universidad Autónoma de Centroamérica (UACA). Cód. MED16955. Correo: dravaleriachacon@gmail.com

\section{INTRODUCCIÓN}

La actinomicosis es una infección causada por una bacteria bacilo gram positiva, anaerobia o aerobia facultativa del género Actinomyces principalmente Actinomyces israelii. La actinomicosis son infecciones crónicas oportunistas, tienen un bajo potencial de virulencia, por lo que se requiere que las barreras mucosas normales estén alteradas como con traumatismos, cirugías o cuerpos extraños. De esta forma, atraviesan la membrana mucosa o superficie epitelial (1). La forma clínica más frecuente de la enfermedades es la cervicofacial, que representa el $60 \%$ de todos los casos, y se asocia a infección odontológica (1). El segundo más común es el genital o pélvico, y su presentación clínica principal es la actinomicosis pélvica. Otros tipos incluyen la torácica, abdominal (apéndice, ciego y colon) y del sistema nervioso central, que se localiza principalmente en el absceso cerebral (2).

Este artículo se enfocará en la infección por Actinomyces en la zona pélvica, en las mujeres. Casi en su totalidad, las infecciones en esta zona causadas por este microorganismo se asocian al uso de un dispositivo intrauterino (DIU). Otras posibles causas incluyen la vaginosis bacteriana, que fomenta un entorno anaeróbico y se asocia con otros microorganismos y la presencia de tumores. Se ha considerado la posibilidad de un contagio a través del sexo oral porque estas bacterias forman parte de la microbiota de la cavidad oral. Los DIU favorecen el crecimiento de organismos que quedan en el exocérvix. Además, modifica el metabolismo de los carbohidratos en las células endometriales, fomentando aún más la inflamación (2).

Este estudio tiene como objetivo describir la relación de los DIU y la actinomicosis pélvica, así como la identificación de la enfermedad y su tratamiento a fin de garantizar un adecuado manejo de la paciente y evitar las complicaciones de la enfermedad.

\section{MÉTODO}

Para la presente revisión se seleccionaron un total de 14 artículos científicos, 12 en español, 1 en portugués y 1 en inglés. Todos fueron consultados de fuentes como Scielo, Redalyc, The Lancet, Us National Library of Medicine National Institutes of Health $y$ Elsevier. Todos los artículos comprenden desde 2004 hasta 2021. Las investigaciones consultadas son de los países: Estados Unidos, Brasil, México, Colombia y España. Las temáticas de los artículos incluyen investigaciones donde se evalúan los tipos de DIU, así como su mecanismo de acción y complicaciones.

También se incluyeron artículos científicos sobre la enfermedad actinomicosis y actinomicosis pélvica. Por último, se encontraron artículos que relacionaran la 
enfermedad en estudio con los DIU, que tuvieran evidencia científica. Se excluye temas como actinomicosis en otros lugares así como otros métodos de anticoncepción.

\section{DISPOSITIVOS INTRAUTERINOS}

La preocupación por el control de la natalidad es una situación que ha hecho que se inventen nuevos y cada vez más efectivos métodos anticonceptivos. Existe documentación de que los DIU se utilizaron antes del siglo XX. El primer DIU fue diseñado por el ginecólogo alemán Richard Richter en 1909 y consistía en un anillo con dos tiras de seda trenzadas y cubiertas de celulosa. Desde este primer modelo, los DIUs han ido evolucionando hasta los mas modernos. Fue en la década de los sesenta cuando el producto se desarrollo en forma de $\mathrm{T}$ puesto que se adaptaba mejor a la forma del útero (3).

EI DIU se puede definir como un elemento sólido que puede ser de varias formas, destinado a ser introducido en la cavidad uterina, a modo de cuerpo extraño, donde ejerce su acción, bien de forma inerte o liberando sustancias, con el objetivo de impedir embarazos no deseados. Constituyen un método anticonceptivo de larga duración, reversible, efectivo y seguro para la mayoría de las mujeres.

\section{Clasificación}

Según sus características, los DIUs pueden ser clasificados como: inertes, liberadores de cobre o liberadores de hormonas. Los DIUs inertes son considerados históricos y no se utilizan en la actuali- dad. No liberan ninguna sustancia y su eficacia está relacionada con el tamaño y el modelo del dispositivo. Los DIU de cobre, como especifica su nombre, libreran cobre. La mayoría son de alta carga (más de $300 \mathrm{~mm}$ ), ya que tienen mayor eficiacia y su tiempo de uso es mayor. Su mecanismo de acción se basa en una reacción inflamatoria en el útero que deriva en producción de leucocitos que fagocitan los espermatozoides. Dicha acción se incrementa por la acción del cobre, el cual es toxico para los espermatozoides y óvulos. También produce disminución de hidratación del moco cervical el cual disminuye la movilidad del esperma (5).

Los DIU liberadores de levonorgestrel (DIULng), están constituidos por plástico y tienen forma de $\mathrm{T}$, con un núcleo medicinal en el eje vertical, que segpun el dispositivo tendrá distinto contenido en levonorgestrel (6). Estos ejercen su efecto por varios mecanismos de acción. Primero, aumentan la viscosidad del moco cervical por la progesterona, por lo que los espermatozoides verán inhibida su migración por el canal cervical. También, adelgazan el endometrio, lo que produce un entorno no favorable para la supervivencia del esperma, así como la fecundación. Por último, se produce la inhibición de la ovulación (4).

\section{Complicaciones del uso de DIU}

Indiscutiblemente, el DIU es un buen método de planificación familiar, desgraciadamente su uso no está libre de complicaciones. Dentro de las más importantes se destacan el sangrado uterino, enfermedad pélvica inflamatoria, dolor pélvico, aborto séptico, embarazo ectópico, migración y perforación uterina.

\section{ENFERMEDAD PÉLVICA INFLAMATORIA}

La enfermedad pélvica inflamatoria (EPI) es la complicación que más se relaciona con la colocación del DIU. El riesgo de que ocurra una infección es 6.3 veces mayor durante los 
primeros 20 días de su inserción y es raro posteriormente, prácticamente resultando en el mismo riesgo que la población general (7). Asimismo, la probabilidad de desarrollar EPI no aumenta con el uso prolongado del dispositivo. Esta complicación es resultado de una infección polimicrobiana, que generalmente incluye bacterias anaerobias del cérvix y de la vagina. La contaminación suele ocurrir durante la inserción del DIU por arrastre de microorganismos, por lo que las infecciones del tracto genital constituyen potenciales factores de riesgo. Las mujeres con contagios asintomáticos por clamidia o gonorrea tienen una alta probabilidad de desarrollar EPI inmediatamente después de la colocación del DIU (8).

EI DIU-Lng probablemente brinde mayor protección contra enfermedades de transmisión sexual (ETS) debido a que produce moco cervical espeso que limita el paso de los microorganismos.

En las usuarias del DIU se encuentran comúnmente enfermedades por microorganismos oportunistas, tal es el caso de Actinomyces, que normalmente está presente en la flora vaginal y aprovecha la reacción inflamatoria producida por el DIU para producir infección (4).

\section{Embarazo ectópico}

El riesgo absoluto de embarazo ectópico con el uso del DIU está aumentado. Con el DIU de cobre entre un 5-10\% podrían ser ectópicos, y con el DIU-Lng la tasa es aún más elevada. En un estudio realizado en el Hospital Nacional Edgardo Rebaglia-ti Martins entre 1998 y 2002, la frecuencia de embarazo ectópico fue de 0,55\% y cinco pacientes $(22,16 \%)$ tenían como antecedente el uso de DIU.

A pesar de esto, existe evidencia de nivel adecuadode que el antecedente de gestación ectópica no es una contraindicación para el uso de DIU (7).

\section{Aborto}

En caso de que el DIU no se retire el riesgo de aborto es de hasta un $50 \%$. La tasa de aborto es 2.5-5 veces mayor que en mujeres no portadoras de DIU y más de la mitad de los abortos espontáneos ocurren en el segundo trimestre.

\section{$\underline{\text { Infertilidad }}$}

El saber cómo afecta el DIU a la fertilidad aún sigue siendo un tema controvertido. En un estudio que incluyó a 205 mujeres se encontró que el $93.6 \%$ lograron embarazarse, demostrando así que no hay evidencia de que el uso del DIU incremente el riesgo de infertilidad (7).

\section{Perforación y migración}

El riesgo de que aparezca esta complicación es de alrededor de 1.3 de 1000 inserciones (7). Habitualmente se presenta cuando existe una pobre experiencia del médico, y las probabilidades de que ocurra son mayores en el puerperio inmediato, postaborto o fuera de la menstruación. Otros factores que se relacionan con su aparición son: el tamaño y orientación del útero (anteversión o retroversión) y la presencia de malformaciones uterinas (9). Cuando se llega a producir una perforación ocurre, de manera secundaria, desplazamiento del DIU a regiones contiguas dentro de la misma pelvis, aunque también puede llegar a migrar a cavidad abdominal o, incluso, al retroperitoneo. Una perforación puede llegar a ser asintomática y por tanto pasar por alto su diagnóstico, además en muchas de las veces puede no ser reconocida de inmediato, motivo por el cual es conveniente volver a examinar a la paciente seis semanas después de la 
inserción del DIU para buscar datos que pudieran indicar que ocurrió esta complicación. Siempre deberá ser sospechada en todo paciente con dolor abdominal de etiología desconocida, hemorragia uterina anormal y ausencia de visualización de los hilos del dispositivo (9).

\section{ACTINOMICOSIS PÉLVICA}

La actinomicosis es una infección bacteriana supurativa crónica, producida por especies de Actinomyces, principalmente Actinomyces israelii, bacilo filamentoso, gram positivo anaerobio, no esporulado que coloniza la orofaringe, el tracto gastrointestinal y el canal vaginal. Generalmente se manifiesta con formación de granulomas absecificados de crecimiento lento, fístulas y fibrosis densa en la modalidad invasiva (10).

Los factores predisponentes son apendicitis perforada, diverticulitis, cuerpo extraño (como DIU y pesario), cirugía previa y neoplasia.

La actinomicosis pélvica se presenta asociada al uso prolongado de DIU sin control en casi toda la totalidad de los casos descritos en mujeres, al actuar como un cuerpo extraño (10).

Inicialmente la actinomicosis pélvica se puede comportar como la enfermedad pélvica inflamatoria (EPI), que al frotis o exploración microbiológica se encontraría el germen causal, encontrándose el Actinomyces. En la mayoría de casos, las pacientes portadoras de EPI, sea cual sea el microorganismo causal, se encuentran asintomáticas, por lo que en el caso de ser su etiología un Actinomyces, con el transcurso del tiempo, dicha infección puede convertirse en una API.

En la API se propaga la infección desde el aparato genital hasta los órganos vecinos, por diseminación contigua mediante granulomas que contienen múltiples colonias de Actinomyces, se origina una masa pélvica fibrosa, descrita como "pelvis congelada o sellada", por la incapacidad de liberar las estructuras comprometidas durante la cirugía (11).

La API se denomina "pseudotumoral" porque se presenta como un tumor pélvico complejo con características imagenológicas inespecíficas, que a menudo se confunden con neoplasia y metástasis que corresponden a la diseminación hematógena a distancia de la infección, por lo que el diagnóstico y el manejo representan un gran desafío para el ginecólogo.

\section{Síntomas}

Los signos y síntomas de la actinomicosis inicialmente son los mismos que una EPI (dolor pélvico, secreción vaginal, dispareunia, entre otros), en general son inespecíficos y de larga evolución. Cuando la enfermedad avanza, las manifestaciones dependen del órgano comprometido. Habitualmente se presenta como una tumoración abdomino-pélvica de consistencia sólida, fija y poco dolorosa. Esta es la forma más frecuente de aparición, asociada con un plastrón pélvico (10). Los otros síntomas frecuentes con los que se relaciona son fiebre baja y dolor abdominal crónico. Puede haber alteración del transito intestinal por compresión extrínseca del tumor, alteraciones de patrón urinario, tenesmo vesical y síntomas de infección del tracto urinario (ITU), por la misma razón. Puede ser confundido con cáncer colorectal o ITU a repetición. Ocasionalmente, hay fístulas internas y externas hacia la pared abdominal y hacia el periné.

Puede haber síntomas que harían sospechar de cáncer de ovario, como 
aumento del diámetro abdominal, por la masa creciente, así como sensación de plenitud pronta y ascitis.

Otros menos frecuentes son la hemoptisis por presencia de granulomatomas pulmonares y alteraciones del sistema nervioso central por la misma razón anterior.

\section{Diagnóstico}

El diagnóstico de la enfermedad se sospecha en toda paciente usuaria de un DIU, habitualmente sin control en la que se sospecha de una EPI, y su frotis demuestra un Actinomyces. En el caso de API, esta se sospecha en pacientes con un DIU y una masa pélvica que a la exploración se encuentra con contornos imprecisos, aplastronado y firme.

Al estudiar a las paciente en primera instancia se pueden realizar imágenes. Iniciando con radiografías, las de tórax pueden mostrar nódulos pulmonares que hagan sospechar de metástasis, sin embargo en el contexto de la enfermedad, éstos corresponden a la diseminación hematógena de la actinomicosis. En una tomografía axial computarizada (TAC) se observaría la masa pélvica y los granulomas diseminados por el resto de los órganos, como el hígado y bazo.

En los exámenes de laboratorio las pacientes con API presentan con frecuencia anemia, leucocitosis, elevación de la velocidad de eritrosedimentacion y de la proteína $\mathrm{C}$ reactiva.

El diagnóstico más próximo se hace cuando el diagnóstico es tardío, con revisión microbiológica de las masas que se extraen tomada por laparotomía exploratoria o toma de biopsia por aspiración. Las piezas quirúrgicas se observan con microabscesos, áreas de hemorragia y con tejido necrótico. Al microscopio se observan gránulos en el pus, tejido o secreciones de la muestra quirúrgica, infiltrado de linfocitos, células plasmáticas, polimorfonucleares y gránulos de azufre que son muy comunes, sin embargo, no patognomónico (13). Para hacer el diagnóstico certero, se realiza por medio de inmunohistoquímica, con anticuerpos monoclonales anti actinomices.

En ocasiones es difícil realizar los estudios mencionados, por lo que entonces se puede detectar mediante un frotis de papanicolaou (aunque tiene $50 \%$ de especificidad), en este se pueden observar bacilos ramificados Gram positivos finos a lo largo de la periferia de los gránulos. Debe tenerse cuidado en la interpretación de las laminillas pues las acumulaciones de espermatozoides y los filamentos de mucina pueden simular gránulos de azufre y las hifas que caracterizan el hallazgo de una infección por Actinomyces (11). En la actualidad el método más certero es la inmunofluorescencia directa (13).

\section{Tratamiento}

El tratamiento de elección es con antibióticos betalactámicos de uso prolongado, por vía intravenosa los primeros días y luego vía oral hasta completar de 3 a 6 meses (11). La penicilina $G$ y amoxacilina, intravenosos y via oral respectivamente son los más utilizados, con adecuada acción antimicrobiana.

La API responde bien a esta terapia, y los tumores suelen desaparecer por completo, lo que confirma que los tumores pélvicos y nódulos pulmonares son por actinomicosis.

Por lo descrito anteriormente no se recomienda la laparotomía quirúrgica, debido al riesgo alto de lesiones iatrogénicas, intestinales y de las vías urinarias, como consecuencia de la adherencia íntima de las vísceras comprometidas. La laparoscopía exploratoria se realiza en caso de duda 
diagnóstica para descartar una neoplasia maligna y tomar muestras para biopsias (14).

\section{CONCLUSIONES}

El uso del DIU ha ido en incremento en los últimos años debido a su gran eficacia para prevenir embarazos no deseados y por tener un bajo costo a largo plazo. Es de importancia que el médico tenga conocimiento elemental sobre la técnica correcta de aplicación, enfatizando en que hay que valorar cada caso, reconociendo cuáles son las principales complicaciones que se presentan con este método y cuál es la forma de evitar y proceder ante las mismas. Esto limitará los daños que el DIU puede ocasionar, incrementando el uso de este método temporal de anticoncepción de una manera más segura.

El uso del DIU es la causa principal de actinomicosis pélvica, y esta es la segunda causa más común de presentación de actinomicosis (3). Esto se da por facilidad de ascenso de las bacterias por los hilos del DIU, y el trauma que produce su colocación, rompiendo la barrera epitelial que trabaja como sistema de protección.

Aunque infrecuente, una de las presentaciones de la actinomicosis pélvica es la actinomicosis pseudotumoral, la cual se confunde con cáncer de órganos pélvico, y su diagnóstico y tratamiento representan un desafío.

Se sospecha en usuarias de DIU por tiempo prolongado que presentan un tumor pélvico abdominal. El diagnóstico se confirma mediante biopsia de muestras obtenidas por laparotomía o laparoscopía exploratoria, punción percutánea o biopsia de endometrio. El compromiso de órganos pélvicos y la extensión de la lesión se establecen con pruebas de imagen.
El tratamiento es con antibióticos de uso prolongado, preferentemente penicilina $G$ y amoxacilina, que logran la remisión total de los tumores. El diagnóstico acertado y oportuno permite el tratamiento eficaz con antibióticos, evita la cirugía y las complicaciones de esta.

\section{Los autores declaran no tener conflicto de interés.}

\section{REFERENCIAS}

1. García, A. Ramírez, N. Sandoval, H. Romero, M. Pelvic Actinomycosis. Canadian Journal of Infectious Diseases and Medical Microbiology. $2017 . \quad 2017(1)$ : 17. https://doi.org/10.1155/2017/9428650

2. Tinoco, I. Aragón, v. Gómez, M. Rodríguez, E.Otras infecciones crónicas. Actinomicosis. Programa de Formación Médica Continuada Acreditado. 2018. 12(53): 3132-3141. https://doi.org/10.1016/j.med.2018.03.022

3. Monterubio, C. Actualidad en dispositivos intrauterinos. Panorama Actual. 2020. 44(437): 1168-1172.

https://gruposdetrabajo.sefh.es/gps/images/storie s/publicaciones/PAM4 2020437 1168-1173 Actualidad-dispositivos-intrauterinos.pdf

4. Apacerida, A. Da Silva, A. Quioato, I. Marques, C. Rejeicao ao uso do dispositivo intrauterino (DIU) como método contraceptivo em mulheres em idade reprodutiva introducao. N. Fórum Inic. Cient. Unifunec. 2018.2318. Https://seer.unifunec.edu.br/index.php/forum/artic le/view/3864

5. Hsia JK, Creinin MD. Intrauterine contraception. Seminars in Reproductive Medicine. 2016; 34(3): 1526-8004. https://pubmed.ncbi.nlm.nih.gov/26947701/

6. Andeyro García M, Modeno Vidal R. Dispositivos intrauterinos liberadores de levonorgestrel. Sociedad Española de Contracepción. 2019. www.sec.es

7. Arias, J. Complicaciones del dispositivo intrauterino. Lux médica. 2012. 7(22): 25-35. https://revistas.uaa.mx/index.php/luxmedica/articl e/view/1524/1427

8. Bednarek PH, Jensen JT. Safety, efficacy and patient acceptability of the contraceptive and noncontra-ceptive uses of the LNG-IUS. Int J Womens 
Health. $\quad$ 2009; $\quad$ 4: $\quad 45-58$.

https://pubmed.ncbi.nlm.nih.gov/21072274/

9. Pérez, V. Mola, M. Navarro, A. Botella, A. Almodóvar, A. Polo, A. López, L. Aznar, G.

10. Perforación uterina y migración vesical de un dispositivo intrauterino. Actas Urológicas

Españolas. 2001. 25(6): 458-461. https://doi.org/10.1016/S0210-4806(01)72653-8.

11. Aymen, M. Arfaoui, R. Khedhri, S. Amine, M. Abdessamia, K. Samaali, K. Fezai, W. Salhi, M. Malek, M. Neii, K. Pelvic actinomycosis: A confusing diagnosis. International Journal of Surgery Case Reports. 2021. 86(12) https://doi.org/10.1016/j.ijscr.2021.106387.

12. Cisterna, $P$, Ovalle, A. Actinomicosis pélvica invasiva. Un desafío para el ginecólogo. Revista Chilena de Obstetricia y Ginecología . 2021. 86(3): np. DOI:10.24875/RECHOG.M21000008

13. Merchán, J. Gómez, H. Actinomicosis abdominal y pélvica: reto diagnóstico y quirúrgico para el cirujano general. Revista colombiana de cirugía. $2010 . \quad 25(1)$ : 56-60. https://www.revistacirugia.org/index.php/cirugia/a rticle/view/130

14. Sánchez, J. Mercado, N. Chilaca, F. Rivera, J. Uso del DIU asociado a la infección secundaria por Actinomyces en tracto genital femenino. Revista española de patología. 2004. 37(4): 383390. http://www.patologia.es/volumen37/vol37num4/pdf\%20patologia\%2037-4/37-04-03.pdf

15. Bustos, G Josa, D. Perea, j. Gualtero, S. Enfermedad pélvica inflamatoria por Actinomyces sp. en paciente con dispositivo intrauterino: reporte de un caso. Revista Infectio. 2016. 20(1). 33-36.

https://doi.org/10.1016/j.infect.2015.07.005 